\title{
Influence of plastic deformation in processes of agglomeration of the diamond hybrid material on structure and hardness of CVD-diamond
}

\author{
A.Shulzhenko, E.Ashkinazi ${ }^{*}$,A.Sokolov, V.Gargin, \\ A.Kotko ${ }^{* *}$, M.Loshak, L.Aleksandrova, V.Tkach, \\ L.Romanko, V.Ralchenko*, V.Konov"
}

V.Bakul Institute for Superhard Materials, National Academy of Sciences of Ukraine, 2 Avtozavodskaya Str., 04074 Kyiv, Ukraine

*A.Prokhorov General Physics Institute, Russian Academy of Sciences, 38 Vavilov Str., 119991 Moscow, Russia

*: I.Frantsevich Institute for Problems of Materials Science, National Academy of Sciences of Ukraine, 3 Krzhizhanovsky Str., 03680 Kyiv, Ukraine

Received April 22, 2014

Results of research of the "light" and "black" CVD diamond structure in hybrid material, which is the CVD diamond covered by polycrystalline diamond shell, are presented. Hardness of the initial CVD diamond and after high pressure-high temperature (HPHT) treatment is defined. Increase of hardness of the "black" CVD-diamond after HPHT-processing at $20 \%$ was found. Electron microscopy was used to determine mechanism of the polycrystalline diamond compound shell binding with the CVD-diamond surface.

Представлены результаты исследования структуры "светлого" и "черного" CVD-алмаза, содержащегося в гибридном материале, представляющего собой CVD-алмаз, заключенный в поликристаллическую алмазную оболочку. Определена твердость исходного CVD-алмаза и после его баротермической (HPHT) обработки. Установлено повышение твердости "черного" CVD-алмаза после НPHT-обработки на $20 \%$. Методами электронной микроскопии установлен механизм соединения алмазной поликристаллической оболочки с поверхностью CVD-алмаза.

Вплив пластичної деформації в процесах спікання алмазного гібридного матеріалу на структуру і твердість CVD-алмаза. О.О.Шульженко, Є.Є.Ашкіназі, О.М.Соколов, В.Г.Гаргін, О.В.Котко, М.Г.Лошак, Л.І.Александрова, В.М.Ткач, Л.О.Романко, В.Г.Ральченко, В.І.Конов.

Представлено результати дослідження структури "світлого" і "чорного" CVD-алмаза, що міститься у гібридному матеріалі, що представляє собою CVD-алмаз, який поміщений у полікристалічну алмазну оболонку. Визначена твердість вихідного CVD-алмаза і після його баротермічної (HPHT) обробки. Встановлено підвищення твердості "чорного" CVD-алмаза після НРНТ-обробки на $20 \%$. Методами електронної мікроскопії встановлено механізм з'єднання алмазної полікристалічної оболонки з поверхнею CVD-алмаза. 


\section{Introduction}

Today the modern material should combine high durability and hardness to possess thermal stability in a wide range of temperature.

In the second half of the last century quick development of material science results in creation of a wide range of materials with high hardness. In this connection, there was a classification need of these materials. So in work [1] it is offered the materials with hardness of 5-20 GPa to attribute to the highly hard materials, which hardness is above of the metal ones; and materials with hardness above $20 \mathrm{GPa}$ (natural corundum) to refer to the superhard ones.

As a result of active studying of formation features of materials with high physical and mechanical characteristics, application of high pressure treatment above $15 \mathrm{GPa}$ [2], using of a nanostructural materials [3] and special methods of material treatment $[4,5]$ the superhard materials list was expanded essentially. In particular the materials with hardness, which is above hardness of natural diamond monocrystal were obtained. So, hardness of the polycrystalline diamond, which is obtained by direct transformation from nanographite at pressure of $25 \mathrm{GPa}$ and temperature $2200 \mathrm{~K}$, is $140 \mathrm{GPa}$ [2]. After heating at a high pressure the hardness of the natural diamond monocrystal of IIA type $(p=4 \mathrm{GPa}$, the $T>1800 \mathrm{~K})$ is 130-150 GPa [5], and the hardness of the CVD diamond monocrystal is $160-180 \mathrm{GPa}$ $(p=5 \mathrm{GPa}, T=1800-2500 \mathrm{~K})[4]$.

In [6] it was shown that hardness of the polycrystalline CVD diamond (light), which is placed inside the shell at high pressures and temperatures, increases in 1.8 times and has a value that is more than $140 \mathrm{GPa}$.

Such hardness value is supposed from calculation of the theoretical (limiting) hardness, which has been done in the paper [7] and according to which the limiting hardness of diamond shouldn't exceed $210 \mathrm{GPa}$.

The experimental data given above allow the polycrystalline CVD diamond to be referred to the superhard materials having hardness $110 \mathrm{GPa}$ and higher. This specified value should be received at hardness measurement by the Vickers pyramid at the indenter load of $9.8 \mathrm{~N}$ and more.

As it is known [8-10], morphology of the grown-up CVD diamond is sensitive to growth conditions (chemical composition of environment and substrate, method and rate of deposition on a substrate, etc.). Depending on perfection the grown-up material can be formed as polycrystal with a high content of structural defects and strong optical absorption (so-called "black diamond"), and as polycrystal with perfect structure of crystalline particles (so-called "light diamond"). The last type of the crystal applies in optics, devices to heat removal and microelectronic devices. But technology of its growth is more difficult and demands special conditions of cultivation, low growth rate and strict control of parameters throughout the all cycle of cultivation that essentially increases their cost. Therefore use of the CVD diamond light polycrystals is inexpedient in production of the tool, in particular the chisel tool, because of their high cost. For this purpose usage of the black polycrystalline CVD diamond is represented to more perspective.

So far there were no works which are devoted to studying the HPHT treatment influence on properties of the black CVD diamond. It represents a great interest to investigate the material behavior in the conditions of high pressures and temperatures during polycrystalline shell formation from the diamond composite thermostable material (DCTM) made of diamond powder in the size of 40,25 and $14 \mu \mathrm{m}$ [11].

The purpose of the present work is to study the substructure of initial light and black CVD diamond and its properties after HPHT-treatment: to reveal the general features and distinctions of the samples substructure, to define hardness (HV), to investigate mechanism of connection between a diamond shell (DCTM) and CVD diamond surface.

\section{Experimental}

As initial materials the light coarse-crystalline and black fine-crystalline CVD diamond plates have been used. The samples were obtained in the A.M.Prokhorov Institute of General Physics of Russian Academy of Sciences by method of sedimentation in methane-hydrogen mixes in microwave plasma [12].

Each plate was divided into two equal parts along length of the sample. One half was fixed in plastic; remained part was baked at the high pressure $(7.7 \mathrm{GPa})$ and temperature $(1600 \mathrm{~K})$ together with micropowder of synthetic diamond of ASM brand and granularity $40 / 28$ according to the technology, which was described in [6]. 
The produced samples were fixed in a metal holder by polypropylene means for the consecutive polishing of their surface with free abrasive (diamond micropowders).

Hardness of the samples was determined by a PMT tester with the diamond pyramid Vickers, which was used as an indenter [13]. Hardness value was identified by the standard formula: $H V=1.8544 P / \mathrm{d}^{2}$, where $P$ is the indenter load; $d-$ arithmetical mean of two diagonals of a print. The hardness measurements were made at the indenter load of 4.9 and 9.8 N. Size of the diagonals of the print was measured by means of an optical microscope "Neofot" under magnification of $800 \times$.

The samples were investigated by method of electronic scanning microscopy with using the raster electronic microscope EVO50XVP, Ultra Plus ("Carl Zeiss", Germany).

Thin particles, which were broken away from the initial samples, were placed on a coal film for research by method of radiography and transmission electronic microscopy in combination with microdiffraction. Not less than ten such particles for each type of the samples were investigated. The broken-away particles were obtained by means of impact destruction of the initial samples at the room temperature.

To determine superficial resistance of the specimens, flowing of electric current between two metal electrodes in the form of hard-alloy probes with a small contact area was investigated depending on applied tension. The metal electrodes were fixed on a plate surface at distance of $0.4 \mathrm{~mm}$. Diameter of the probe contact was determined by area of the probe print and it was $30 \mu \mathrm{m}$. The distance between probes was a constant for different samples that allowed using value of superficial resistance to compare conductivity of the samples. Value of superficial resistance was measured at ohmic part of volt-ampere characteristics.

\section{Results and discussion}

Results of the hardness measuring of the initial black CVD diamond and covered ones by DCHRM shell are presented in Table 1 . The given values of hardness are average result over 3-9 measurements.

As it is seen from the Table 1 , hardness of the black CVD diamond fixed in the DCTM shell under high-pressure and hightemperature increases $20 \%$ at the indenter load of $4.9 \mathrm{~N}$ and $18 \%$ at the load of $9.8 \mathrm{~N}$.
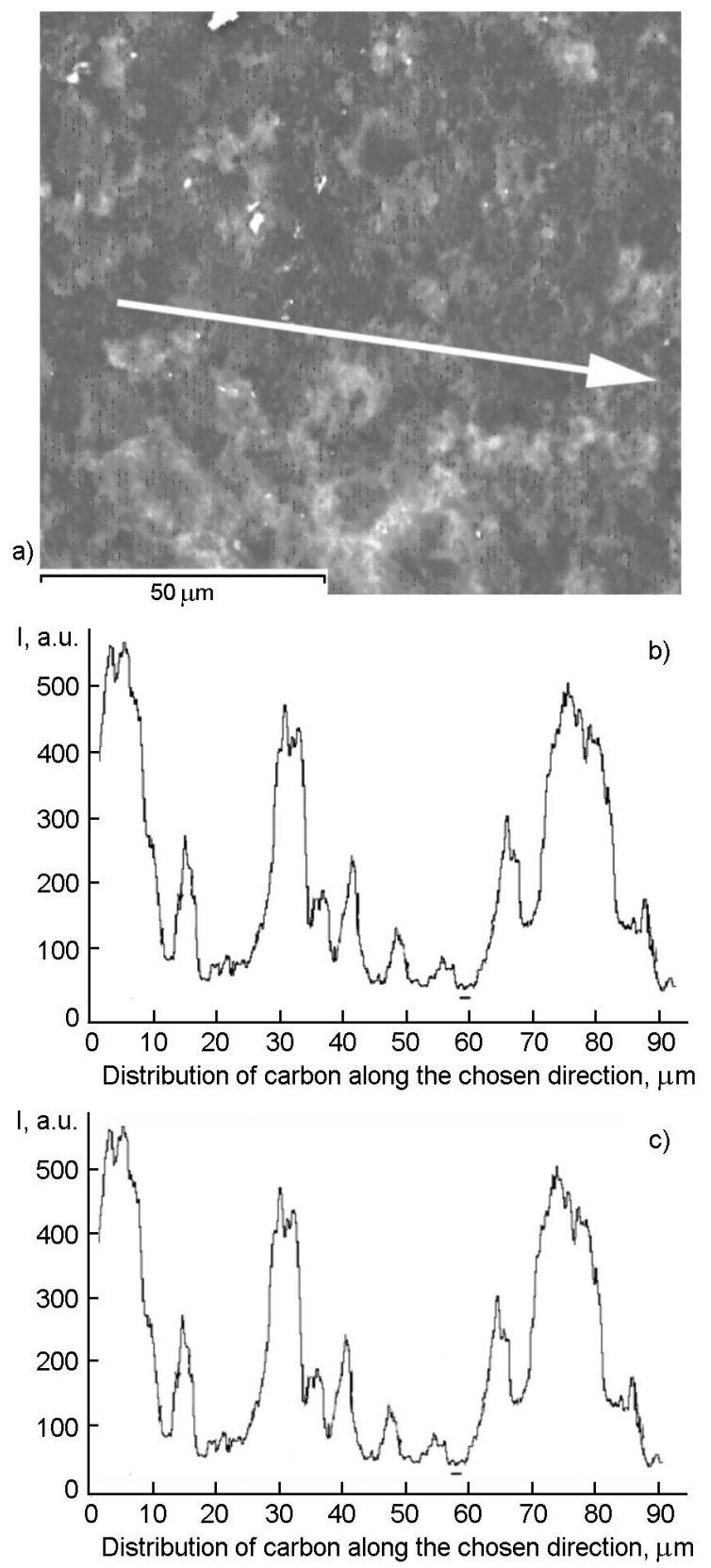

Fig. 1. Image in secondary electrons of CVD diamond surface in hybrid material (a) and distribution of elements along the chosen direction (arrow): b - carbon; $\mathrm{c}-$ silicon.

Table 1. Hardness (HV) of black CVD diamond

\begin{tabular}{|c|c|c|}
\hline \multirow{2}{*}{ Material } & \multicolumn{2}{|c|}{$\begin{array}{c}\text { Hardness (HV) under } \\
\text { an indenter load, N }\end{array}$} \\
\cline { 2 - 3 } & 4.9 & 9.8 \\
\hline Initial, fixed in plastic & 92 & 87 \\
\hline $\begin{array}{c}\text { After HPHT treatment, } \\
\text { inside DCTM shell }\end{array}$ & 115 & 105 \\
\hline
\end{tabular}



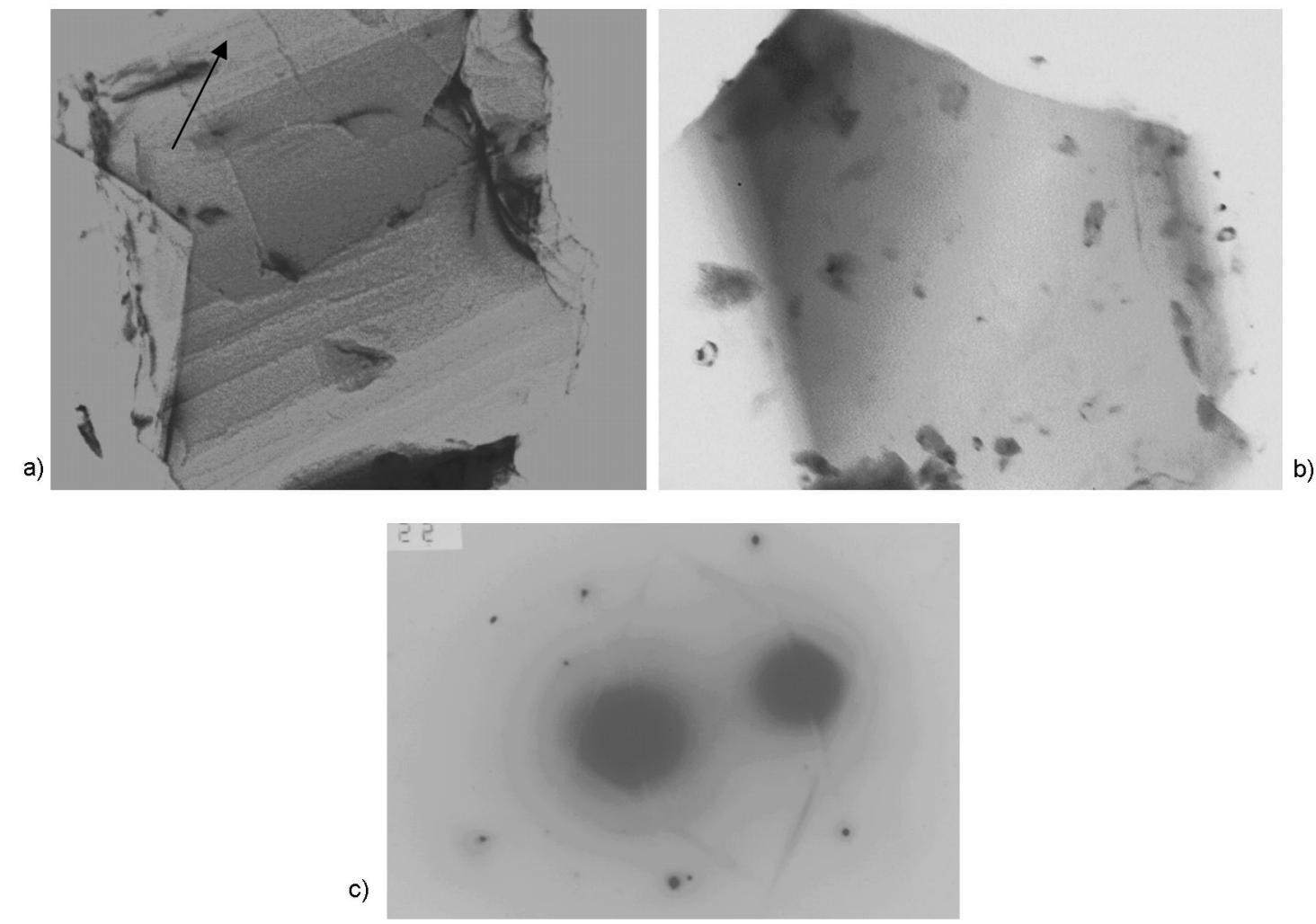

Fig. 2. Typical electronic microscopy images of initial diamond particles (a), twinning of crystals is specified by arrow; micro-electronic patter (c) for the particle given on (b).

In [6] results of the hardness measurement for the light CVD diamond plates on the nucleating side are given; it is $77 \mathrm{GPa}$. Hardness of the same plate, which is placed inside of DCHRM shell, after the high-pressure-high-temperature treatment, has much higher value of 142 and $139 \mathrm{GPa}$ at the indenter load of 4.9 and $9.8 \mathrm{~N}$, respectively. The given values of hardness are average result over 3-5 measurements, the mean-root-square error in the determination didn't exceed $2.5 \%$.

To study the process of interaction between powder grains of the synthetic diamond, which is forming a polycrystalline shell, an activating additive of silicon and black CVD diamond in the course of agglomeration under the high pressure and temperature the sample with partially removed DCHRM shell was prepared (Fig. 4). The sample was studied by method of electron scanning microscopy with use of raster microscope EVO50XVP, Ultra Plus ("Carl Zeiss", Germany). Surfaces of the CVD diamond and DCTM shell were investigated. The data are shown in Fig. 1.
From the experimental data we find that connection of the diamond shell (DCTM) and CVD diamond is provided generally due to silicon (silicon carbide).

Results of the study of all types diamond samples by means of transmission electronic microscopy in combination with microdiffraction are presented in Fig. 2-8. It was found that particles of the initial samples of light CVD diamond were actually free from defects. Dislocations and packing defects were not identified. In some particles twinning of the crystals were observed. Thickness of the twinning layers was $0.1-0.3 \mu \mathrm{m}$ (Fig. 2a). In the images the high crystal perfection of the diamond is confirmed by presence of the Kikuchi lines for the most part of the particles that is a diagnostic sign of the high-perfect crystals (Fig. 2c).

After deformation under HTHP treatment the main feature of the light CVD diamond was an existence of internal boundaries disorientation. It was evident available contrast of the particles and feature of microscopic images: black and white contrast or wide curve contours were observed, and main reflections were looked 
a)
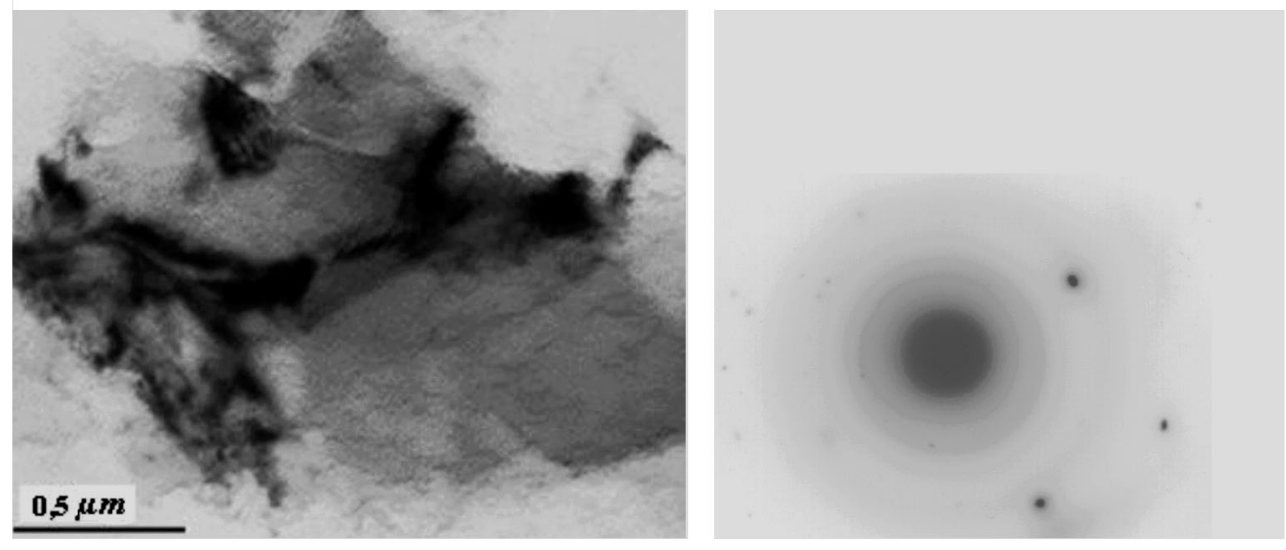

b)

Fig. 3. Electronic microscopy image of a particle with internal boundary of disorientation (a) and micro-electronic patter for the particle (b).

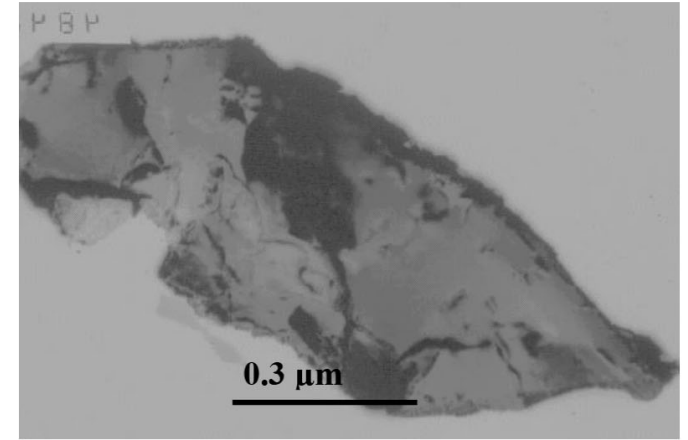

a)

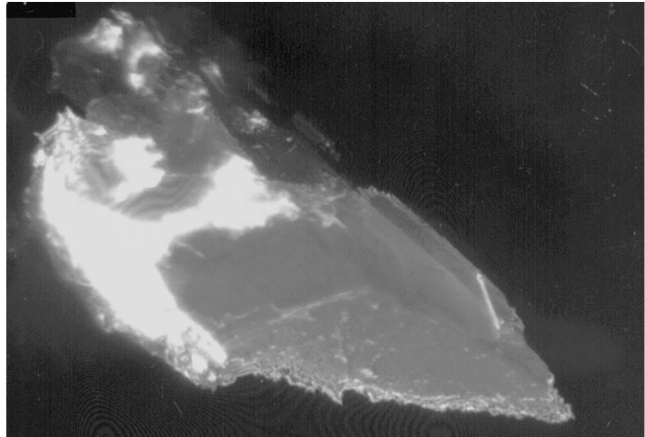

b)

c)

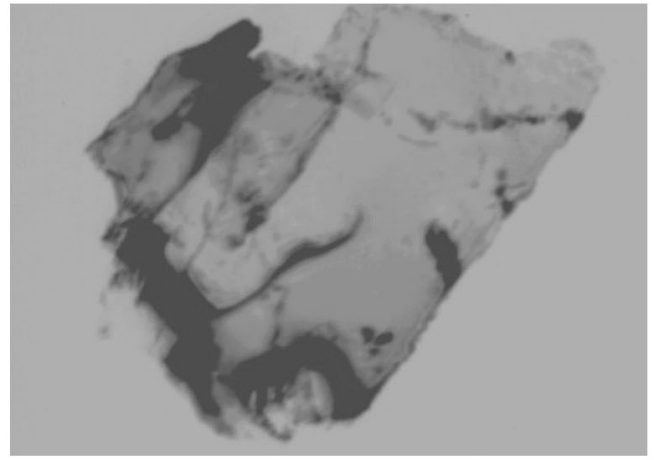

Fig. 4. Electronic microscopy image of diamond particles with dislocations.

like small arcs in the images (oriented edge in Fig. 3); also individual dislocations or their groups (Fig. 4a) were seen.

Besides the mentioned above features of the diamond substructure the stacks of package defects were observed also. In some cases the high density of the package defects resulted in diamond disorientation. Visible in microscopic images continuous cords in layers, which are parallel to [111] direction, indicate it (Fig. 5). Appearance of the internal boundaries and disorientation in the light CVD diamond after HPHT treatment, groups of dislocations and stacks of the package defects causes the change of electro-physical properties of the material. In particular, superficial electro-resistance decreased; it was $R>10^{10} \mathrm{Ohm}$ for the initial material and $R \sim 10^{7} \mathrm{Ohm}$ after the HPHT treatment.

The samples of the initial black CVD diamond contained grains of three structural states. The substructure of the light CVD diamond was characteristic for the first state (see Fig. 3 and Fig. 6). Content of such particles in the samples bulk was about $80 \%$.

Diamond of the second structural state was presented in the form of fine-grained 

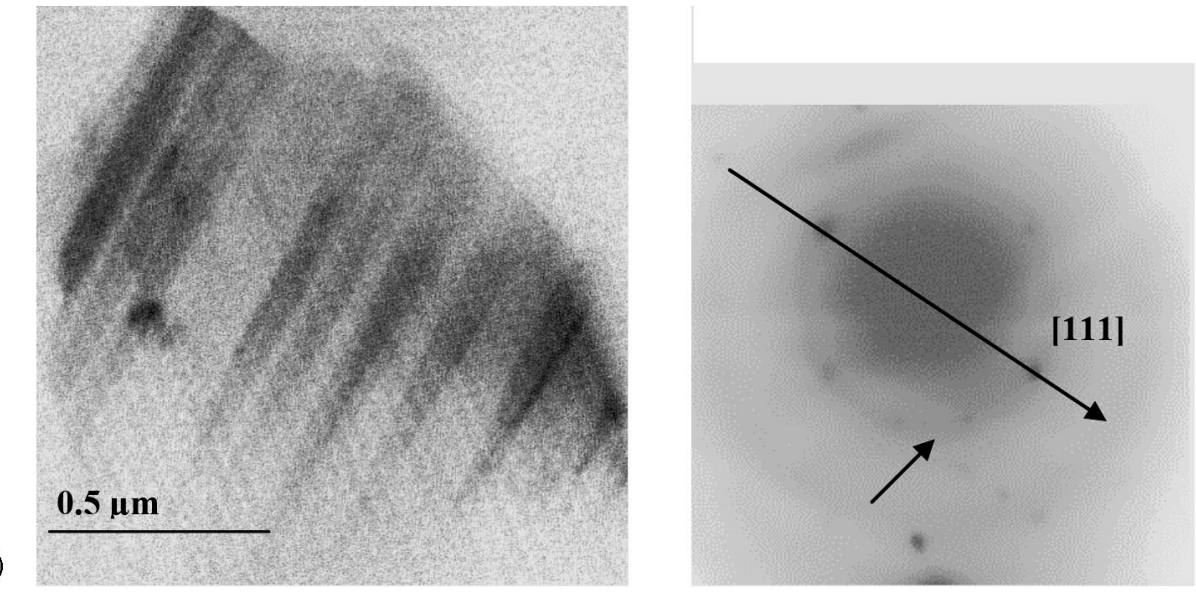

b)

Fig. 5. Package defects in diamond particle (a) and micro-electronic patter for the particle (b), layer with continuous cords is specified by arrow.

agglomerates with cubic array. The range of the grains sizes was $10-30 \mathrm{~nm}$.

Diamond of the third structural state was presented in the form of areas with cubic and hexagonal diamond array. Such areas differed by a dispersion grade and substructural features. The area with the fragmented microdomain substructure that is characteristic for diamond particles of two basic polymorphic types (cubic and hexagonal) being in crystal-oriented bond is shown.

General content of the particles of the second and third structural type in the black CVD diamond was about $50 \%$.

After deformation under the HTHP treatment it has been found changes in the particles of the main component only. The study shows that the same substructure, as well as for the deformed light CVD diamond, was characteristic for it, i.e. formation of the package defects and internal

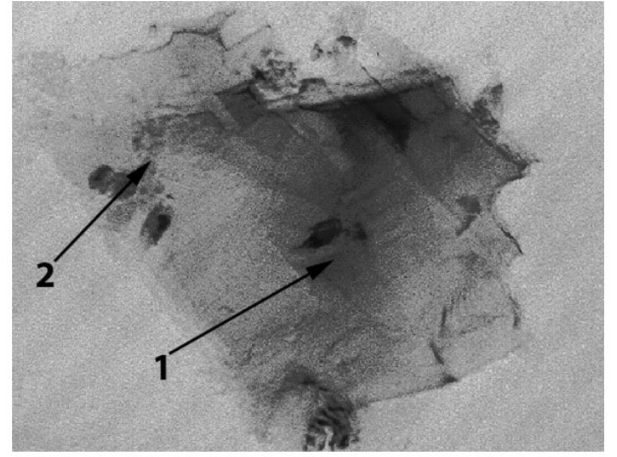

Fig. 6. Electronic microscopy image of the removed particle, which consist of perfect diamond area (1) and nanodisperse grains (2).

boundaries of disorientation takes place. For example in dark field mode the image of the sample, which contains the fragmented and nanodispersed diamond, is presented in Fig. 7 and 8. Structural transfor-

Table 2. Hardness (HV) of CVD diamond depending on structure and conditions of high pressure and high temperature (HPHT) treatment

\begin{tabular}{|c|c|c|c|c||}
\hline \multirow{2}{*}{ Structure of CVD diamond } & \multirow{2}{*}{$\begin{array}{c}\text { Hardness } \\
(\mathrm{HV}), \mathrm{GPa}\end{array}$} & \multicolumn{2}{|c|}{ Treatment conditions } & Reference \\
\cline { 3 - 5 } & & $P, \mathrm{GPa}$ & $T, \mathrm{~K}$ & \\
\hline Monocrystal & $140-180$ & $>5$ & $>1800$ & {$[5]$} \\
\hline Light coarse-crystalline polycrystal & $139-140^{*}$ & 7.7 & 1600 & {$[6]$} \\
\hline Black fine-crystalline polycrystal & $105-115^{*}$ & 7.7 & 1600 & present work \\
\hline Black fine-crystalline polycrystal & $87-92$ & & initial & present work \\
\hline Light coarse-crystalline polycrystal & $\sim 77^{* *}$ & \multicolumn{2}{|c|}{ initial } & {$[6]$} \\
\hline
\end{tabular}

* - CVD-diamond in the polycrystalline DCTM shell

$* *$ - changing in hardness at the germinal side. 

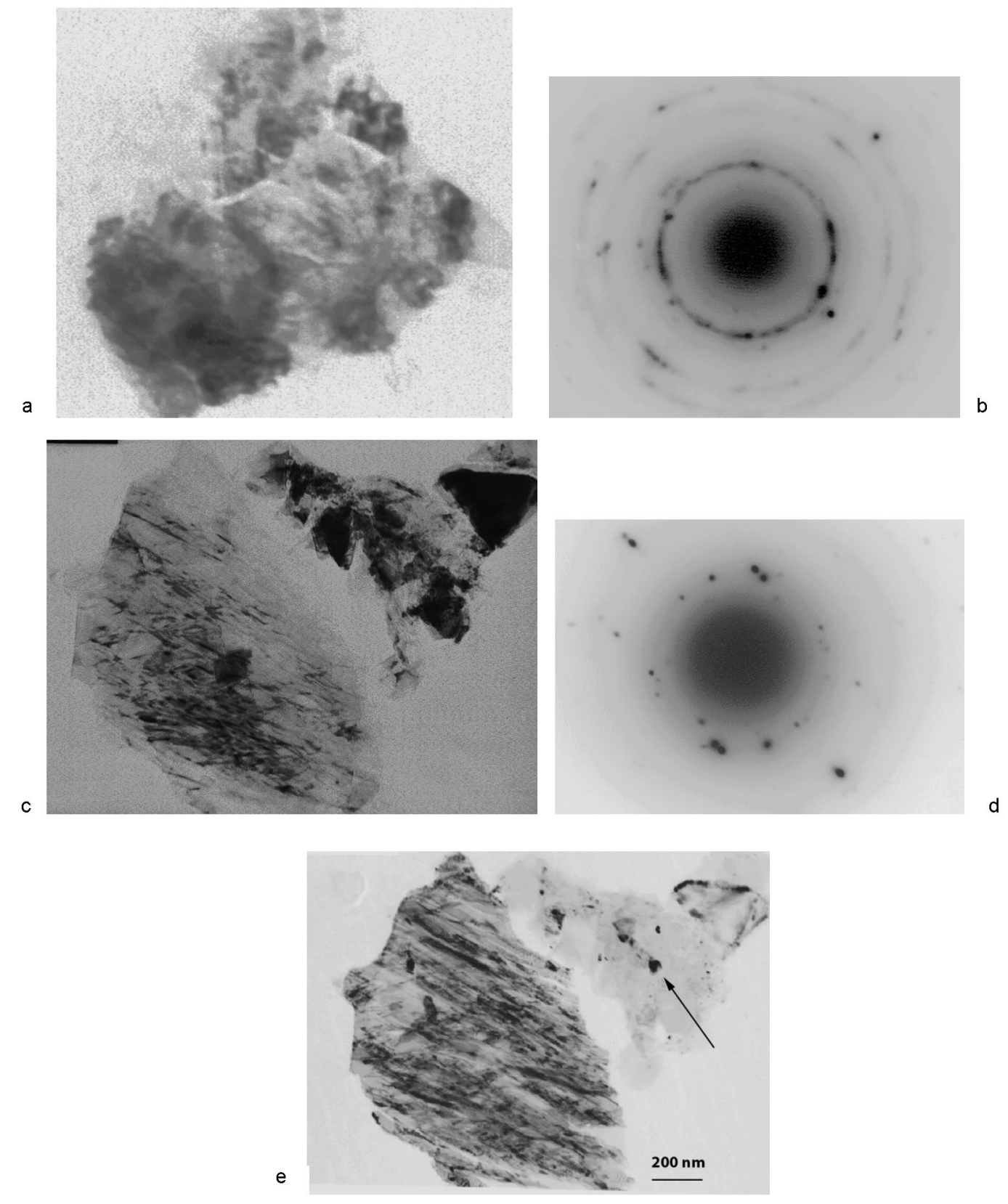

Fig. 7. Typical substructure of diamond particles with cubic and hexagonal array: area of nanodisperse structure and micro-electronic pattern for it ( $a$ and $b$ ), area with microdomain substructure: the light field image and micro-electronic pattern (c and d), the dark field image of a particle with microdomain substructure and area of nanodispersed structure (e).

mation in the diamond of two other states wasn't revealed.

Values of hardness (HV) for the CVD diamond in dependent of structure and conditions of the HPHT treatment are given in Table 2. The experimental data given above for the polycrystalline CVD diamond substructure changes allow to get conclusion that the reason of the hardness growth is deformation hardening of the material under the HPHT treatment.
Earlier [6] by means of studying of the combinational dispersion spectrum for the CVD diamond we came to assumption that the hardness increases in the process of hybrid ultrahard polycrystalline composite material formation. The process of the hard shell formation around the CVD diamond is accompanied by the plastic deformation of diamond grains that results in creation of a complicated structural tension in it under the high pressure. The similar conclusion 


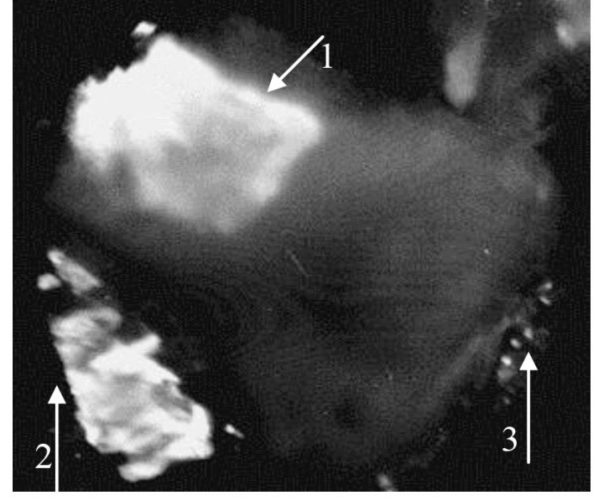

Fig. 8. Substructure of a removed particle, which contains diamond areas with internal boundaries (arrow 1, 2) and nanodisperse part (arrow 3).

was made due to the optical microscopy data, which is presented in work [9] for monocrystal of CVD diamond with use of the crossed polarizers. It was found that the hardness growth under the high temperature and pressure treatment results in extension of the internal tension in the monocrystal.

\section{Conclusions}

It was shown that substructure of the light polycrystalline CVD diamond is changed after HPHT treatment; it is changed from actually nondefective particles to the structure with internal boundaries of disorientation, groups of dislocations, stacks of package defects, etc. In particular, it takes the form of superficial electroresistance reduction of the polycrystal.

After the HPHT treatment three types of state were revealed for the black polycrystalline CVD diamond. The first was the state with a typical for light CVD diamond substructure; the second phase was in the form of the fine-grained particles with cubic diamond array; the third phase was in the form of the areas with cubic and hexagonal diamond array.

For the black CVD diamond the hardness increased by $20 \%$ after the HPHT processing.

The experimental data on change of the polycrystalline CVD diamond substructure due to influence of the high pressure and temperatures allows coming to the conclusion that the reason of the hardness growth is the deformation of material hardening.

\section{References}

1. Synthetic Superhard Materials: in 3 parts. V.1. Synthesis of Superhard Materials, ed. by N.V.Novikov, Naukova Dumka, Kiev (1986) [in Russian].

2. S.Hitoshi, T.Irifune, J.Jap.Soc. Powder and Powder Metallurgy, 53, 452 (2006).

3. A.N.Sokolov, A.A.Shulzhenko, V.G.Gargin, Russian Chemical Journal, 50, 50 (2006).

4. US Patent Application 20030230232 (2003).

5. US Patent 7,115,241 (2006).

6. A.A.Shulzhenko, E.E.Ashkinazi, A.N.Sokolov et al., Superhard Mater., 5, 3 (2010).

7. S.A.Firstov, T.G.Rogul, Reports of National Acad. of Sci. Ukraine, 4, 110 (2007).

8. V.Ralchenko, L.Nistor, E.Pleuler et al., Diamond Relat.Mater., 12, 1964 (2003).

9. Russia Patent 2,389,833 (2010).

10. S.A.Ivanov, // http://www.intactive.ru/ru/info/articles/article $/ 4 /$.

11. A.A.Shulzhenko, R.K.Bogdanov, V.G.Gargin et al., Rock-destroying and the Metal-cutting Tool-equipment and Technology of its Manufacturing and Application, Collection of Scientific Papers thereof (2007), p.189.

12. V.I.Ral'chenko, E.E.Ashkinazi, Instrumentalny Svit, 3, 14 (2005).

13. V.M.Glazov, V.N.Vigdorovich, Microhardness of Metals and Semiconductors, Metallurgy (1969). 